\title{
Association between copy number variation of complement component $C 4$ and Graves' disease
}

\author{
Yu-Huei Liư ${ }^{1,2}$, Lei Wan 1,3,4, Chwen-Tzuei Chang ${ }^{5,6}$, Wen-Ling Liao' ${ }^{1}$ Wen-Chi Chen², Yuhsin Tsai ${ }^{3}$, Chang-Hai Tsai ${ }^{7,8}$ \\ and Fuu-Jen Tsai ${ }^{1,3,7,9,10,11^{*}}$
}

\begin{abstract}
Background: Gene copy number of complement component C4, which varies among individuals, may determine the intrinsic strength of the classical complement pathway. Presuming a major role of complement as an effecter in peptide-mediated inflammation and phagocytosis, we hypothesized that C4 genetic diversity may partially explain the development of Graves' disease (GD) and the variation in its outcomes.
\end{abstract}

Methods: A case-control study including 624 patients with GD and 160 healthy individuals were enrolled. CNV of $C 4$ isotypes (C4A and C4B) genes were performed by quantitative real-time polymerase chain reaction analysis. Statistical comparison and identification of CNV of total $C 4, C 4$ isotypes (C4A and $C 4 B)$ and $C 4$ polymorphisms were estimated according to the occurrence of GD and its associated clinical features.

Results: Individuals with 4, 2, and 2 copies of $C 4, C 4 A$ and $C 4 B$ genes, especially those with A2B2 polymorphism may associate with the development of $\mathrm{GD}(\mathrm{p}=0.001, \mathrm{OR}=10.994,95 \% \mathrm{Cl}: 6.277-19.255 ; \mathrm{p}=0.008, \mathrm{OR}=1.732$, $95 \%$ Cl: $1.190-2.520 ; \mathrm{p}=2.420 \times 10-5, \mathrm{OR}=2.621,95 \% \mathrm{Cl}: 1.791-3.835 ;$ and $p=1.395 \times 10^{-4}, \mathrm{OR}=2.671,95 \% \mathrm{Cl}:$ 1.761-4.052, respectively). Although the distribution of copy number for total C4, C4 isotypes as well as C4 polymorphisms did not associate with the occurrence of goiter, nodular hyperplasia, GO and myxedema, $<2$ copies of C4A may associate with high risk toward vitiligo in patients with $\mathrm{GD}(p=0.001, \mathrm{OR}=5.579,95 \% \mathrm{Cl}$ : 1.659-18.763).

Conclusions: These results may be further estimated for its clinical application on GD and the vitiligo in patients with GD.

\section{Background}

Graves' disease (GD) is an organ-specific autoimmune thyroid disease [1]. It has been known that multiple factors, including the host's genetic factors as well as environmental factors, contribute to the etiology and severity of GD $[2,3]$. However, other forms of variation that might affect gene expression should also be considered.

A new paradigm in human genetics is high frequencies of interindividual variation in the copy number $(\mathrm{CN})$ of specific genomic DNA segments. Copy number variation $(\mathrm{CNV})$ loci often contain genes engaged in host-environment interactions, including those involved in immune functions, which results in susceptibility or resistance to

\footnotetext{
* Correspondence: d0704@mail.cmuh.org.tw

'Department of Medical Genetics and Medical Research, China Medical University Hospital, Taichung, Taiwan

Full list of author information is available at the end of the article
}

autoimmune diseases [4-7], however, no significant association has been found between $\mathrm{CNV}$ and GD [6].

Complement component C4 (C4), located on chromosome $6 \mathrm{q} 21.3$, is encoded by 2 separate loci in the major histocompatibility complex class III region and derives 2 functionally distinct $C 4 A$ and $C 4 B$ isoforms [8]. The complement system is the main element of innate immunity and is regarded as the first line of defense against intrinsic and extrinsic antigens, leading to peptidemediated inflammation, opsonization leading phagocytosis, the direct lysis of antigens [9]. Presuming a major role of complement as an effecter in peptide-mediated inflammation and phagocytosis, we hypothesized that $C 4$ genetic diversity may partially explain the development of GD as well as the variation in its outcomes. Here we investigated the polymorphic variants of $C 4$ that correlate with predisposition to this disease.
C Biomed Central 


\section{Methods}

\section{Patients and healthy individuals}

A total of 624 patients (227 with GO and 397 without GO) with a confirmed diagnosis of GD and an appropriate control group with 160 healthy volunteers from China Medical University Hospital in Taiwan were enrolled and followed actively. All individuals provided informed consent as approved by the ethics committee of China Medical University Hospital. For the patients, diagnosis of GD and GO was followed the criteria set previously [10]. Full medical record abstraction was conducted to obtain demographics (age and gender); treatment and clinical features are summarized in Table 1 . For the healthy individuals, those with matched for gender according to the female predominance of GD including 32 male (20.0\%) and 128 female $(80.0 \%)$. Age was different in healthy $(27.4 \pm 6.4$ years $)$ as compared to the patients with GD $(41.1 \pm 12.9$ years $)\left(\mathrm{p}=1.96 \times 10^{-34}\right)$.

\section{Genomic DNA extraction and quantification gene dosage of $C 4 A$ and $C 4 B$}

Genomic DNA was extracted from peripheral blood following the manufactory's suggestions (Qiagen). C4 gene dosage was assessed by quantitative real-time TaqMan ${ }^{\circledR}$ PCR analysis (Applied Biosystems) as described in the previously published protocols with some modification [11]. Real-time PCR analysis was performed in 96-well optical plates on a $7900 \mathrm{HT}$ real-time PCR system (Applied Biosystems). Primers and probes specific for $C 4 A$, and $C 4 B$ (common $C 4 A$ and $C 4 B$ forward primer "C4F": 5'-GCA GGA GAC ATC TAA CTG GCT TCT-3'; common $C 4 A$ and $C 4 B$ reverse primer " $C 4 R$ ": 5'-CCG CAC CTG CAT GCT CCT-3”; probe "C4A“: FAM-ACC CCT GTC CAG TGT TAG; probe "C4B": FAM-ACC TCT CTC CAG TGA TAC. TaqMan ${ }^{\circledR}$ Universal PCR Master Mix, No AmpErase ${ }^{\circledR}$ uracil-DNA glycosylase (ABI catalog number 4326614), VIC-conjugated TaqMan ${ }^{\circledR}$ RNase $P$ control reagents (ABI catalog number 4316844), $250 \mathrm{nM}$ of the respective FAM-conjugated TaqMan $^{\circledR}$ probes $(C 4 A$ or $C 4 B)$, the particular primers (300 nM C4A or $C 4 B$ ) in distilled water was contained in each of the distinct PCR batches. Appropriately prediluted genomic DNA (threshold cycle $\left[\mathrm{C}_{\mathrm{T}}\right]$ values for RNase P between 24 and 30 ) was added before start. CN of each target gene in each sample was determined from three separated experiments. Thermal cycler conditions were adjusted as follows: initial denaturation step for 10 minutes at $95^{\circ} \mathrm{C} ; 40$ cycles including denaturation for 15 seconds at $95{ }^{\circ} \mathrm{C}$; and annealing/extension for 1 minute for $60^{\circ} \mathrm{C}$. The data were analyzed using SDS 2.3 software (Applied Biosystems).

The $C_{\mathrm{T}}$ value of RNase $P, C 4 A$ or $C 4 B$ was converted into a raw gene dosage by the formula $\mathrm{nRAW}_{C 4 X}=2$ (CTRNase P)-(CTC4X)+1, where $C 4 X$ referred to $C 4 A$ or $C 4 B$.
Raw gene dosages of positive controls selected from the reference panel were plotted versus the actual gene dosages, and the resulting calibration curve served for determination of the actual copy number of unknown samples of this particular run.

\section{Statistical analysis}

Statistical analysis was performed using the statistical package PASW for Windows (version 18.0; SPSS Inc.). The demographics of patients and healthy individuals were analyzed by the chi-square analysis. For those with $2 \times 2$ contingency tables, differences in the incidence of individuals with $C 4$ gene $\mathrm{CNs}$ above and below the median or $C 4 A-C 4 B$ polymorphisms between patients with or without indicated feature were evaluated using Fisher's exact test. For those above $2 \times 2$ contingency tables, differences in the incidence of individuals with $C 4$ gene $\mathrm{CNs}$ above and below the median or $C 4 A-C 4 B$ polymorphisms between patients with or without indicated feature were evaluated using Fisher's exact test, and the two-tailed $p$ value was estimated by 100,000 Monte Carlo simulations with 99\% confidence intervals (CI) (99\% confidence for the simulation result). Odds ratios (ORs) and 95\% CIs were estimated from logistic regression models adjusting for confounding variables as shown in Table 1.

\section{Results}

CNV of C4 genes is associated with susceptibility to GD

The distribution of copy number for total C4, C4 isotypes as well as $C 4$ polymorphisms according to the presence of GD is shown in Table 2. No individuals had a full deficiency of $C 4$ alleles. After adjusting for age, individuals with 4 copies of $C 4$ gene were more susceptible to GD ( $p=0.001, \mathrm{OR}=10.994,95 \% \mathrm{CI}: 6.277-19.255)$ as compared to those without, whereas those with $<4$ copies of $C 4$ gene tended to prevent from GD $(p=0.003$, OR $=$ $0.512,95 \% \mathrm{CI}: 0.338-0.776)$ as compared to those without. The distribution of $C 4 A$ and $C 4 B$ among individuals with or without GD was further investigated. For $C 4 A$ gene, individuals with 2 copies of $C 4 A$ increased the risk toward GD ( $p=0.008, \mathrm{OR}=1.732,95 \% \mathrm{CI}: 1.190-2.520)$ whereas those with $<2$ copies of $C 4 A$ reduced the risk toward GD ( $p=0.01, \mathrm{OR}=0.584,95 \% \mathrm{CI}$ : 0.360-0.948). For $C 4 B$ gene, individuals with 2 copies of $C 4 B$ increased the risk toward GD $\left(p=2.420 \times 10^{-5}, \mathrm{OR}=2.621,95 \%\right.$ CI: 1.791-3.835) whereas those without 2 copies of $C 4 B$ reduced the risk toward GD $(p=0.008$, OR $=0.487,95 \%$ CI: $0.322-0.738$ for those with $<2$ copies $C 4 B ; p=0.015$, $\mathrm{OR}=0.545$, 95\% CI: $0.347-0.856$ for those with $>2$ copies $C 4 B$ respectively). Polymorphism analysis indicated tat individuals with the most common polymorphism (37.3\%), A2B2, with 2.671-fold risk toward GD ( $p=1.395$ $\left.\times 10^{-4}, \mathrm{OR}=2.671,95 \% \mathrm{CI}: 1.761-4.052\right)$ as compared to 
Table 1 Background and demographic characteristics of patients with Graves' disease

\begin{tabular}{|c|c|c|c|c|c|c|c|c|c|c|c|}
\hline \multirow[t]{2}{*}{ Patients' characteristics } & \multirow[t]{2}{*}{ Healthy (160) } & \multirow[t]{2}{*}{ GD (624) } & \multicolumn{2}{|c|}{ Myxedema } & \multirow[t]{2}{*}{ P-value } & \multicolumn{2}{|c|}{ GO } & \multirow[t]{2}{*}{ P-value } & \multicolumn{2}{|c|}{ Vitiligo } & \multirow[t]{2}{*}{ P-value } \\
\hline & & & No & Yes & & No & Yes & & No & Yes & \\
\hline \multicolumn{12}{|l|}{ Age at diagnosis } \\
\hline$\leq 40$ & $145(90.6)$ & 307 (49.2) & $247(47.0)$ & $59(60.2)$ & 0.017 & $182(45.8)$ & $125(55.1)$ & 0.027 & $239(46.9)$ & 68 (59.6) & 0.014 \\
\hline$>40$ & $15(9.4)$ & $317(50.8)$ & $278(53.0)$ & 39 (39.8) & & $215(54.2)$ & $102(44.9)$ & & $271(53.1)$ & $46(40.4)$ & \\
\hline \multicolumn{12}{|l|}{ Gender } \\
\hline Male & $32(20.0)$ & $133(21.3)$ & $110(21.0)$ & $22(22.4)$ & 0.739 & $74(18.6)$ & $59(26.0)$ & 0.031 & $107(21.0)$ & $26(22.8)$ & 0.700 \\
\hline Female & $128(80.0)$ & $491(78.7)$ & $415(79.0)$ & 76 (77.6) & & $323(81.4)$ & $168(74.0)$ & & $403(79.0)$ & $88(77.2)$ & \\
\hline \multicolumn{12}{|l|}{ Treatment } \\
\hline \multicolumn{12}{|l|}{ Radioiodine } \\
\hline No & & $601(96.3)$ & $504(96.0)$ & $96(98.0)$ & 0.345 & $389(98.0)$ & $212(93.4)$ & 0.003 & $489(95.9)$ & $112(98.2)$ & 0.226 \\
\hline Yes & & $23(3.7)$ & $21(4.0)$ & $2(2.0)$ & & $8(2.0)$ & $15(6.6)$ & & $21(4.1)$ & $2(1.8)$ & \\
\hline \multicolumn{12}{|l|}{ Thyroid gland surgery } \\
\hline No & & $564(90.4)$ & $472(89.9)$ & $91(92.9)$ & 0.363 & $363(91.4)$ & $201(88.5)$ & 0.239 & $457(89.6)$ & $107(93.9)$ & 0.164 \\
\hline Yes & & $60(9.6)$ & $53(10.1)$ & $7(7.1)$ & & $34(8.6)$ & $26(11.5)$ & & $53(10.4)$ & $7(6.1)$ & \\
\hline \multicolumn{12}{|l|}{ Clinical features } \\
\hline \multicolumn{12}{|l|}{ Goiter } \\
\hline Grade 1-3 & & $146(23.5)$ & $119(22.8)$ & $27(27.6)$ & 0.309 & $101(25.5)$ & $46(20.4)$ & 0.154 & $117(23.1)$ & $30(26.3)$ & 0.462 \\
\hline Grade 4-5 & & $474(76.5)$ & $403(77.2)$ & $71(72.4)$ & & $295(74.5)$ & $179(79.6)$ & & $390(76.9)$ & $84(73.7)$ & \\
\hline \multicolumn{12}{|l|}{ Nodular hyperplasia } \\
\hline No & & $483(77.5)$ & $434(82.7)$ & $49(50.5)$ & $2.880 \times 10^{-12}$ & $301(75.8)$ & $182(80.5)$ & 0.175 & $430(84.3)$ & $53(46.9)$ & $6.670 \times 10^{-18}$ \\
\hline Yes & & $140(22.5)$ & $91(17.3)$ & $49(49.5)$ & & $96(24.2)$ & $44(19.5)$ & & $80(15.7)$ & $60(53.1)$ & \\
\hline \multicolumn{12}{|l|}{ Myxedema } \\
\hline No & & $525(74.3)$ & & & & $305(76.8)$ & $220(97.3)$ & $1.35 \times 10^{-11}$ & $507(99.4)$ & $18(15.9)$ & $8.900 \times 10^{-8}$ \\
\hline Yes & & $98(25.7)$ & & & & & $92(23.2)$ & $6(2.7)$ & & $3(0.6)$ & $95(84.1)$ \\
\hline \multicolumn{12}{|l|}{ Graves' ophthalmopathy } \\
\hline No & & 397 (63.6) & $305(58.0)$ & $92(93.9)$ & $1.350 \times 10^{-11}$ & & & & $295(57.8)$ & $102(89.5)$ & $2.200 \times 10^{-10}$ \\
\hline Yes & & $227(36.4)$ & $220(41.9)$ & $6(6.1)$ & & & & & $215(42.2)$ & $12(10.5)$ & \\
\hline \multicolumn{12}{|l|}{ Vitiligo } \\
\hline No & & $510(81.7)$ & 507 (96.6) & $3(3.1)$ & $8.900 \times 10^{-8}$ & $295(74.3)$ & $215(94.7)$ & $2.204 \times 10^{-10}$ & & & \\
\hline Yes & & $114(18.3)$ & $18(3.4)$ & 95 (96.9) & & $102(25.7)$ & $12(5.3)$ & & & & \\
\hline
\end{tabular}

Abbreviations: GD, Graves, disease; GO, Graves' ophthalmopathy; SD, standard deviation; N, number. 
Table 2 Distribution of C4 polymorphisms in individuals with or without Graves' disease

\begin{tabular}{|c|c|c|c|c|c|}
\hline \multirow[t]{2}{*}{ Variations } & \multicolumn{2}{|c|}{ GD } & \multirow{2}{*}{ 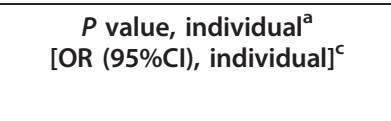 } & \multirow[t]{2}{*}{$P$ value $^{b}$} & \multirow[t]{2}{*}{ OR $(95 \% C l)^{d}$} \\
\hline & No, N (\%) & Yes, N (\%) & & & \\
\hline \multicolumn{6}{|l|}{ C4 CNV } \\
\hline 4 & 57 (35.6) & $314(50.3)$ & 0.001 [10.994 (6.277-19.255)] & 0.002 & (Reference) \\
\hline$<4$ & $52(32.5)$ & $134(21.5)$ & $0.003[0.512(0.338-0.776)]$ & & $0.389(0.245-0.615)$ \\
\hline$>4$ & $51(31.9)$ & $176(28.2)$ & 0.361 & & $0.497(0.317-0.780)$ \\
\hline \multicolumn{6}{|l|}{ C4A CNV } \\
\hline 2 & $83(51.9)$ & $395(63.3)$ & 0.008 [1.732 (1.190-2.520)] & 0.011 & (Reference) \\
\hline$<2$ & $33(20.6)$ & $79(12.7)$ & 0.010 [0.584 (0.360-0.948)] & & $0.509(0.307-0.843)$ \\
\hline$>2$ & $44(27.5)$ & $150(24.0)$ & 0.365 & & $0.628(0.404-0.977)$ \\
\hline \multicolumn{6}{|l|}{ C4B CNV } \\
\hline 2 & $67(41.9)$ & $377(60.4)$ & $2.420 \times 10^{-5}[2.621(1.791-3.835)]$ & $1.328 \times 10^{-4}$ & (Reference) \\
\hline$<2$ & $53(33.1)$ & $143(22.9)$ & $0.008[0.487(0.322-0.738)]$ & & $0.374(0.240-0.584)$ \\
\hline$>2$ & $40(25)$ & $104(16.7)$ & $0.015[0.545(0.347-0.856)]$ & & $0.391(0.241-0.636)$ \\
\hline \multicolumn{6}{|c|}{ C4 polymorphisms } \\
\hline $\mathrm{A} 2 \mathrm{~B} 2$ & 39 (24.4) & $254(40.7)$ & $1.395 \times 10^{-4}[2.671(1.761-4.052)]$ & $3.87 \times 10^{-6}$ & (Reference) \\
\hline $\mathrm{A} 2 \mathrm{~B} 1$ & $22(13.8)$ & $78(12.5)$ & 0.672 & & $0.409(0.219-0.763)$ \\
\hline A3B2 & $16(10.0)$ & $64(10.3)$ & 0.924 & & $0.539(0.273-1.064)$ \\
\hline A2B3 & $5(3.1)$ & $44(7.1)$ & 0.067 & & $0.961(0.343-2.697)$ \\
\hline A3B1 & $10(6.3)$ & $32(5.1)$ & 0.574 & & $0.373(0.159-0.876)$ \\
\hline A1B2 & $6(3.8)$ & $34(5.4)$ & 0.384 & & $0.687(0.257-1.836)$ \\
\hline Other & $62(38.8)$ & 118 (18.9) & & & $0.242(0.148-0.396)$ \\
\hline
\end{tabular}

Abbreviations: GD, Graves' disease; CNV, copy number variation; OR, odds ratio; $\mathrm{Cl}$, confidence interval; N, number.

${ }^{a}$ Individual C4 CNVs and polymorphisms between individuals with or without GD were evaluated by Fisher's exact test using $2 \times 2$ contingency tables.

${ }^{b}$ CNV of $C 4, C 4 A$ and $C 4 B$ between individuals with or without GD were evaluated by Fisher's exact test using $3 \times 2$ contingency tables.C4 polymorphisms

between individuals with or without GD were evaluated by Fisher's exact test using $7 \times 2$ contingency tables. The $p$ value was estimated by 100,000 Monte Carlo simulations with $99 \%$ confidence intervals $(\mathrm{Cl})$.

${ }^{\mathrm{C}} \mathrm{ORs}$ and $95 \% \mathrm{Cls}$ were estimated from logistic regression models adjusting for age.

${ }^{\mathrm{d}} \mathrm{ORs}$ and $95 \% \mathrm{Cls}$ were estimated from logistic regression models adjusting for age.

those without. These results indicate that individuals with 4, 2 and 2 copies of $C 4, C 4 A$ and $C 4 B$ genes, especially those with A2B2 polymorphism may have higher risk, whereas those with $<4,<2$ and $\neq 2$ copies of $C 4, C 4 A$ and $C 4 B$ genes may have lower risk toward GD, respectively.

\section{CNV of C4 genes did not significantly associated with myxedema and GO}

We also estimated the association between polymorphism of $C 4$ genes and clinical features of GD. CNV of C4 genes showed association with susceptibility toward GO, vitiligo and myxedema, but not goiter or nodular hyperplasia as estimated by Fisher's exert test (data not shown). After adjusting for age, nodular hyperplasia, GO, and vitiligo, the distribution of copy number for total $C 4$, $C 4$ isotypes as well as $C 4$ polymorphisms did not associate with the occurrence of myxedema (Table 3 ).

The distribution of copy number for total C4, C4 isotypes as well as $C 4$ polymorphisms according to the presence of GO is shown in Table 4. The relationship between $C 4 \mathrm{CNV}$ status and GO was not significant ( $p=$ 0.396). The distribution of $C 4 A$ and $C 4 B$ among GD patients with and without GO were further investigated. After adjusting for age, gender, radioiodine treatment, vitiligo and myxedema, neither isotypes nor polymorphisms of $C 4$ was significantly associated with $\mathrm{GO}$, although GD patients with $<2$ copies ( 0 or 1$)$ of the $C 4 A$ gene were less susceptible to $\mathrm{GO}(p=0.014, \mathrm{OR}=0.549,95 \% \mathrm{CI}$ : 0.303-0.998) as compared to those with 2 copies of $C 4 A$, and those with $\mathrm{A} 3 \mathrm{~B} 1$ polymorphism were less susceptible to $\mathrm{GO}(p=0.001, \mathrm{OR}=0.374,95 \% \mathrm{CI}: 0.146-0.960)$ as compared to those with A2B2 polymorphism. These results indicate that neither isotypes nor polymorphisms of $C 4$ was significantly associated with $\mathrm{GO}$, however, as compared to GD patients with 2 copies of $C 4 A$ or those with A2B2 polymorphism, those with $<2$ copies of $C 4 A$ or those with $\mathrm{A} 3 \mathrm{~B} 1$ might be protected against the development of GO, respectively.

\section{GD patients with $<2$ copies of $C 4 A$ had higher risk toward vitiligo}

The distribution of copy number for total $C 4, C 4$ isotypes as well as $C 4$ polymorphisms according to the presence of vitiligo is shown in Table 4. After adjusting with age, nodular hyperplasia, GO and myxedema, patients with 
Table 3 Distribution of C4 polymorphisms in Graves' disease patients with or without myxedema

\begin{tabular}{|c|c|c|c|c|c|}
\hline \multirow[t]{2}{*}{ Variations } & \multicolumn{2}{|c|}{ Myxedema } & \multirow{2}{*}{ 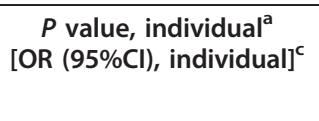 } & \multirow[t]{2}{*}{$P$ value ${ }^{b}$} & \multirow[t]{2}{*}{ OR $(95 \% \mathrm{Cl})^{d}$} \\
\hline & No, N (\%) & Yes, N (\%) & & & \\
\hline \multicolumn{6}{|l|}{ C4 CNV } \\
\hline 4 & $265(50.5)$ & $48(49.0)$ & 0.826 & & (Reference) \\
\hline$<4$ & $100(19.0)$ & $34(34.7)$ & $0.001[1.884(0.538-6.597)]$ & $4.900 \times 10^{-4}$ & $1.714(0.447-6.575)$ \\
\hline$>4$ & $160(30.5)$ & $16(16.3)$ & $0.005[0.617(0.166-2.289)]$ & & $0.761(0.186-3.122)$ \\
\hline \multicolumn{6}{|l|}{ C4A CNV } \\
\hline 2 & $336(64.0)$ & $58(59.2)$ & 0.364 & & (Reference) \\
\hline$<2$ & $57(10.9)$ & $22(22.5)$ & $0.003[0.627(0.164-2.404)]$ & 0.008 & $0.511(0.122-2.134)$ \\
\hline$>2$ & $132(25.1)$ & $18(18.4)$ & 0.159 & & $0.496(0.117-2.106)$ \\
\hline \multicolumn{6}{|l|}{ C4B CNV } \\
\hline 2 & $317(60.4)$ & $59(60.2)$ & 1 & & (Reference) \\
\hline$<2$ & $115(21.9)$ & $28(28.6)$ & 0.152 & 0.168 & $1.163(0.298-4.542)$ \\
\hline$>2$ & $93(17.7)$ & $11(11.2)$ & 0.072 & & $0.552(0.125-2.443)$ \\
\hline \multicolumn{6}{|c|}{ C4 polymorphisms } \\
\hline $\mathrm{A} 2 \mathrm{~B} 2$ & $217(41.3)$ & $36(36.7)$ & 0.434 & 0.050 & (Reference) \\
\hline $\mathrm{A} 2 \mathrm{~B} 1$ & $63(12.0)$ & $15(15.3)$ & 0.405 & & $1.895(0.307-11.710)$ \\
\hline A3B2 & $58(11.0)$ & $6(6.1)$ & 0.202 & & $1.371(0.163-11.522)$ \\
\hline A2B3 & $41(7.8)$ & $3(3.1)$ & 0.130 & & $0.558(0.029-10.789)$ \\
\hline A3B1 & $26(5.0)$ & $6(6.1)$ & 0.619 & & $0.333(0.032-3.499)$ \\
\hline A1B2 & $23(4.4)$ & $11(11.2)$ & 0.013 [1.094 (0.137-8.709)] & & 1.009 (0.103-9.841) \\
\hline Other & $97(18.5)$ & $21(21.4)$ & & & $0.735(0.163-3.310)$ \\
\hline
\end{tabular}

Abbreviations: GD, Graves' disease; GO, Graves' ophthalmopathy; CNV, copy number variation; OR, odds ratio; $\mathrm{Cl}$, confidence interval; $\mathrm{N}$, number.

${ }^{a}$ Individual C4 CNVs and polymorphisms between GD patients with or without myxedema were evaluated by Fisher's exact test using $2 \times 2$ contingency tables.

${ }^{\mathrm{b}}$ CNV of C4, C4A and C4B between GD patients with or without myxedema were evaluated by Fisher's exact test using $3 \times 2$ contingency tables.C4

polymorphisms between GD patients with or without myxedema were evaluated by Fisher's exact test using $7 \times 2$ contingency tables. The $p$ value was estimated by 100,000 Monte Carlo simulations with $99 \%$ confidence intervals (Cl).

${ }^{\mathrm{C}} \mathrm{ORs}$ and $95 \% \mathrm{Cls}$ were estimated from logistic regression models adjusting for age, nodular hyperplasia, GO and vitiligo.

${ }^{\mathrm{d}} \mathrm{ORs}$ and $95 \% \mathrm{Cls}$ were estimated from logistic regression models adjusting for age, nodular hyperplasia, GO and vitiligo.

$<2$ copies of $C 4 A$ had a 5.153 -fold increased risk of vitiligo $\left(p=2.650 \times 10^{-4}, \mathrm{OR}=5.153,95 \% \mathrm{CI}: 1.629-16.300\right)$. It remained significant even when compared with GD patients with 2 copies of $C 4 A(p=0.001, \mathrm{OR}=5.579$, 95\% CI: 1.659-18.763, Table 5). These results indicate that $<2$ copies of $C 4 A$ may increase the risk for vitiligo in patients with GD.

\section{Discussion}

Several functionally relevant single nucleotide polymorphisms are characteristic of GD and GO $[12,13]$, but no relevant $\mathrm{CNV}$ has been reported [14]. In the present study, we found that the $C N V$ of $C 4, C 4 A$ or $C 4 B$ may associate with the development of GD. In addition, $<2$ copies of $C 4 A$ may associate with development of vitiligo in patients with GD. To the best of our knowledge, this is the first study to report that the linkage among CNV of $C 4$ genes, GD and GD-associated vitiligo. Our results provide new information which may be applied clinically.

$\mathrm{C} 4$ involves in the classical pathway which is triggered by interaction of the Fc portion of an antibody or C-reactive protein with $\mathrm{C} 1 \mathrm{q}$. It has been shown that the copy number of $C 4, C 4 A$ or $C 4 B$ positively correlated with the protein levels of total $\mathrm{C} 4, \mathrm{C} 4 \mathrm{~A}$ or $\mathrm{C} 4 \mathrm{~B}$, respectively [7]. In our results, individuals with 4,2 , and 2 copies of $C 4, C 4 A$ or $C 4 B$ have higher risk whereas those with deficiencies of $C 4, C 4 A$ or $C 4 B$ have lower risk toward GD. One possibility is that a deficiency of complement may lead to ineffective opsonization, lytic activity or impairment of B-cell memory, by which reduce tissue injury [15]. Unfortunately, the mechanisms by which $C 4$ abnormality contributes to the protection of organ-specific autoimmunity are poorly understood. Nevertheless, whether a potential gene-gene or gene-environment interaction is involved in susceptibility to GD needs to be further investigated [16]. This study provides a substantial amount of data that may help to clarify the role of $C 4$ genes in this disorder. It is only through investigations of diverse populations that researchers can expect to dissect the complex genetics involved. In addition, functional studies of susceptibility genes using appropriate animal models could allow for an assessment of their role in the disease process.

However, it may play a different regulatory role in systemic autoimmune diseases. Low level of C4 complements in sera has been found in several autoimmune diseases [17-21]. In addition, the presence of $C 4 A$ null 
Table 4 Distribution of C4 polymorphisms in Graves' disease patients with or without Graves' ophthalmopathy

\begin{tabular}{|c|c|c|c|c|c|}
\hline \multirow[t]{2}{*}{ Variations } & \multicolumn{2}{|c|}{ GO } & \multirow{2}{*}{ 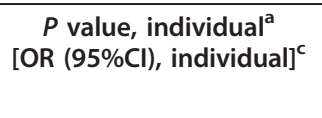 } & \multirow[t]{2}{*}{$P$ value ${ }^{b}$} & \multirow[t]{2}{*}{ OR $(95 \% \mathrm{Cl})^{\mathrm{d}}$} \\
\hline & No, $N(\%)$ & Yes, N (\%) & & & \\
\hline \multicolumn{6}{|l|}{ C4 CNV } \\
\hline 4 & $196(49.4)$ & $118(52.0)$ & 0.561 & 0.396 & (Reference) \\
\hline$<4$ & $92(23.2)$ & $42(18.5)$ & 0.188 & & $0.978(0.614-1.558)$ \\
\hline$>4$ & $109(27.5)$ & $67(29.5)$ & 0.581 & & $1.029(0.687-1.540)$ \\
\hline \multicolumn{6}{|l|}{ C4A CNV } \\
\hline 2 & $238(39.9)$ & $157(69.2)$ & $0.025[1.436(0.994-2.075)]$ & 0.014 & (Reference) \\
\hline$<2$ & $61(15.4)$ & $18(7.9)$ & $0.008[0.590(0.328-1.059)]$ & & $0.549(0.303-0.998)$ \\
\hline$>2$ & $98(24.7)$ & $52(22.9)$ & 0.628 & & $0.772(0.509-1.169)$ \\
\hline \multicolumn{6}{|l|}{ C4B CNV } \\
\hline 2 & $229(57.7)$ & $148(65.2)$ & 0.074 & 0.186 & (Reference) \\
\hline$<2$ & $97(24.4)$ & $46(20.3)$ & 0.276 & & $0.806(0.520-1.249)$ \\
\hline$>2$ & $71(17.9)$ & $33(14.5)$ & 0.316 & & $0.697(0.430-1.132)$ \\
\hline \multicolumn{6}{|c|}{ C4 polymorphisms } \\
\hline $\mathrm{A} 2 \mathrm{~B} 2$ & $149(37.5)$ & $105(46.3)$ & 0.035 [1.283 (0.900-1.828)] & 0.005 & (Reference) \\
\hline $\mathrm{A} 2 \mathrm{~B} 1$ & $53(13.4)$ & $25(11.0)$ & 0.451 & & $0.796(0.449-1.411)$ \\
\hline A3B2 & $37(9.3)$ & $27(11.9)$ & 0.338 & & $1.067(0.596-1.912)$ \\
\hline A2B3 & $29(7.3)$ & $15(6.6)$ & 0.871 & & $0.734(0.366-1.476)$ \\
\hline $\mathrm{A} 3 \mathrm{~B} 1$ & $25(6.3)$ & $7(3.1)$ & 0.091 & & $0.374(0.146-0.960)$ \\
\hline A1B2 & $28(7.1)$ & $6(2.6)$ & $0.026[0.451(0.176-1.160)]$ & & $0.374(0.153-1.056)$ \\
\hline Other & 65 (16.4) & $40(17.6)$ & & & $0.894(0.549-1.455)$ \\
\hline
\end{tabular}

Abbreviations: GD, Graves' disease; GO, Graves' ophthalmopathy; CNV, copy number variation; OR, odds ratio; $\mathrm{Cl}$, confidence interval; $\mathrm{N}$, number.

andividual C4 CNVs and polymorphisms between GD patients with or without GO were evaluated by Fisher's exact test using $2 \times 2$ contingency tables.

${ }^{\mathrm{b}} \mathrm{CNV}$ of $C 4, C 4 A$ and $C 4 B$ between GD patients with or without GO were evaluated by Fisher's exact test using $3 \times 2$ contingency tables.C4 polymorphisms between GD patients with or without GO were evaluated by Fisher's exact test using $7 \times 2$ contingency tables. The $p$ value was estimated by 100,000 Monte Carlo simulations with $99 \%$ confidence intervals $(\mathrm{Cl})$.

'ORs and $95 \% \mathrm{Cls}$ were estimated from logistic regression models adjusting for age, gender, ever received radioiodine treatment, myxedema and vitiligo. ${ }^{\mathrm{d}} \mathrm{ORs}$ and $95 \% \mathrm{Cls}$ were estimated from logistic regression models adjusting for age, gender, ever received radioiodine treatment, myxedema and vitiligo.

allele that results in partial C4 deficiency have shown to be risk factor for susceptibility in systemic lupus erythematosus (SLE) and the SLE-related renal damage $[7,19]$. A hypothesis is that complement may participate in the presentation of self-antigens to developing B cells by which protects against responses to self-antigens and subsequence promoting the elimination of self-reactive lymphocytes [9]. The pathogenesis of vitiligo, similar to SLE, is characterized by the destruction of cutaneous melanocytes which due to another antibody-induced hypopigmentation. Experiments in knockout mice have demonstrated that complement deficient can cause the destruction of pigment cells leading to vitiligo-like depigmentation [21]. Our results revealed that deficiency of $C 4 A$ may enhance the development of vitiligo in GD patients, implying exist of an alternative pathway for the deficiency of complement.

What is interesting is that although we explored the relationship of $C 4 \mathrm{CNV}$ to GD as well as other GD clinical features, only the lower copies of $C 4 A$, but not $C 4 B$, were associated with higher risk of vitiligo. Because it appears that $\mathrm{C} 4 \mathrm{~A}$ binds to amino group-containing antigens such as immune complex, whereas $\mathrm{C} 4 \mathrm{~B}$ binds to hydroxyl group-containing antigens such as bacteria, this result may provide another view to support the hypotheses that the pathogenesis of vitiligo may be more relevant to the existence of the immune complex than the pathogen. In addition, recent studies have identified that the risk locus within the major histocompatibility complex region on chromosome $6 \mathrm{q}$ may be associated with vitiligo in both Chinese Han population and American population [22,23]. It may be interesting to investigate the gene-gene interaction between $\mathrm{C} 4$ polymorphism and the vitiligo risky locus. Moreover, although confirmation of these results in larger samples is warranted, it would be interesting to further investigate the functional role of $C 4 A$ in the development of vitiligo.

\section{Conclusion}

This study provides evidence that the CNV of $C 4, C 4 A$ or $C 4 B$ may associate with the development of GD and $<2$ copies of $C 4 A$ may associate with development of vitiligo in patients with GD. These results may be further estimated for its application on predicting the occurrence of GD and the clinical outcome in patients 
Table 5 Distribution of C4 polymorphisms in Graves' disease patients with or without vitiligo

\begin{tabular}{|c|c|c|c|c|c|}
\hline \multirow[t]{2}{*}{ Variations } & \multicolumn{2}{|c|}{ Vitiligo } & \multirow{2}{*}{ 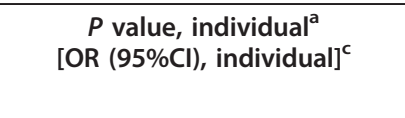 } & \multirow[t]{2}{*}{$P$ value ${ }^{b}$} & \multirow[t]{2}{*}{ OR $(95 \% C l)^{d}$} \\
\hline & No, $N(\%)$ & Yes, N (\%) & & & \\
\hline \multicolumn{6}{|l|}{ C4 CNV } \\
\hline 4 & $258(50.6)$ & $56(49.1)$ & 0.836 & 0.002 & (Reference) \\
\hline$<4$ & $97(19.0)$ & $37(32.5)$ & $0.002[1.297(0.434-3.874)]$ & & $1.334(0.415-4.289)$ \\
\hline$>4$ & $155(30.4)$ & $21(18.4)$ & $0.011[0.987(0.362-2.691)]$ & & $1.076(0.370-3.133)$ \\
\hline \multicolumn{6}{|l|}{ C4A CNV } \\
\hline 2 & $330(64.7)$ & $65(57.0)$ & 0.133 & & (Reference) \\
\hline$<2$ & $52(10.2)$ & $27(23.7)$ & $2.650 \times 10^{-4}[5.153(1.629-16.3000]$ & 0.001 & $5.579(1.659-18.763)$ \\
\hline$>2$ & $128(25.1)$ & $22(19.3)$ & 0.225 & & $1.289(0.414-4.013)$ \\
\hline \multicolumn{6}{|l|}{ C4B CNV } \\
\hline 2 & $310(60.8)$ & $67(58.8)$ & 0.751 & & (Reference) \\
\hline$<2$ & $112(22.0)$ & $31(27.2)$ & 0.267 & 0.414 & $1.133(0.355-3.614)$ \\
\hline$>2$ & $88(17.3)$ & $16(14.0)$ & 0.487 & & $2.107(0.687-6.467)$ \\
\hline \multicolumn{6}{|c|}{ C4 polymorphisms } \\
\hline A2B2 & $213(41.8)$ & $41(36.0)$ & 0.292 & 0.03 & (Reference) \\
\hline $\mathrm{A} 2 \mathrm{~B} 1$ & $62(12.2)$ & $16(14.0)$ & 0.638 & & $0.889(0.175-4.524)$ \\
\hline A3B2 & $57(11.2)$ & $7(6.1)$ & 0.125 & & $0.756(0.132-4.335)$ \\
\hline A2B3 & $40(7.8)$ & $4(3.5)$ & 0.154 & & $1.111(0.151-8.205)$ \\
\hline A3B1 & $25(4.9)$ & $7(6.1)$ & 0.638 & & $1.484(0.199-11.089)$ \\
\hline A1B2 & $22(4.3)$ & $12(10.5)$ & $0.019[2.035(0.335-12.368)]$ & & $2.745(0.384-19.599)$ \\
\hline Other & $91(17.8)$ & $27(23.7)$ & & & $3.471(1.046-11.525)$ \\
\hline
\end{tabular}

Abbreviations: GD, Graves' disease; GO, Graves' ophthalmopathy; CNV, copy number variation; OR, odds ratio; $\mathrm{Cl}$, confidence interval; $\mathrm{N}$, number.

andividual C4 CNVs and polymorphisms between GD patients with or without vitiligo were evaluated by Fisher's exact test using $2 \times 2$ contingency tables.

${ }^{b}$ CNV of $C 4, C 4 A$ and C4B between GD patients with or without vitiligo were evaluated by Fisher's exact test using $3 \times 2$ contingency tables.C4 polymorphisms between GD patients with or without vitiligo were evaluated by Fisher's exact test using $7 \times 2$ contingency tables. The $p$ value was estimated by 100,000 Monte Carlo simulations with $99 \%$ confidence intervals (Cl).

${ }^{\mathrm{C}} \mathrm{ORs}$ and $95 \% \mathrm{Cls}$ were estimated from logistic regression models adjusting for age, nodular hyperplasia, myxedema and GO.

${ }^{\mathrm{d}} \mathrm{ORs}$ and $95 \% \mathrm{Cls}$ were estimated from logistic regression models adjusting for age, nodular hyperplasia, myxedema and GO.

with GD which might aid in the diagnosis of the disease and the development of therapeutic strategies.

\section{List of abbreviations}

(GD): Graves' disease; (GO): Graves' ophthalmopathy; (CNV): copy number variation; (CN): copy number; (SLE): systemic lupus erythematosus.

\section{Acknowledgements}

We thank Hsin-Hui Chen for the technical assistance in preparation of DNA and analyzing the variations. This study was supported by grants from the National Science Council (96-2628-B-039-002-MY3 and 98-2320-B-039-008MY3), Taipei, Taiwan, and grants from the China Medical University Hospital (DMR-100-162), Taichung, Taiwan.

\section{Author details}

'Department of Medical Genetics and Medical Research, China Medical University Hospital, Taichung, Taiwan. ${ }^{2}$ Graduate Institute of Integrated Medicine, China Medical University, Taichung, Taiwan. ${ }^{3}$ School of Chinese Medicine, China Medical University, Taichung, Taiwan. ${ }^{4}$ Department of Health and Nutrition Biotechnology, Asia University, Taichung, Taiwan. ${ }^{5}$ Division of Endocrinology and Metabolism, Department of Medicine, China Medical University Hospital, Taichung, Taiwan. ${ }^{6}$ Department of Endocrinology and Metabolism, College of Chinese Medicine, China Medical University, Taichung, Taiwan. ${ }^{7}$ Department of Pediatrics, China Medical University Hospital, Taichung, Taiwan. ${ }^{8}$ Department of Biotechnology, Asia University, Taichung, Taiwan. ${ }^{9}$ School of Post-Baccalaureate Chinese Medicine, China Medical University, Taichung, Taiwan. ${ }^{10}$ Department of Biotechnology, Asia
University, Taichung, Taiwan. ${ }^{11}$ Department of Biotechnology and Bioinformatics, Asia University, Taichung, Taiwan.

\section{Authors' contributions}

YHL designed the study, managed the literature searches, undertook the statistical analysis, and wrote the draft of the manuscript. LW designed and performed the experiments. CTC and WCC recruited and maintained the clinical information of participants. LWLL and TYT undertook the statistical analysis. CHT and FJT directed the study and reviewed the results. All authors contributed to and have approved the final manuscript.

\section{Competing interests}

The authors declare that they have no competing interests.

Received: 22 February 2011 Accepted: 26 September 2011 Published: 26 September 2011

\section{References}

1. Mishra A, Mishra SK: Multicentre study of thyroid nodules in patients with Graves' disease (Br J Surg 2000; 87: 1111-13). Br J Surg 2001, 88(2):313.

2. Tomer $\mathrm{Y}$, Huber $\mathrm{A}$ : The etiology of autoimmune thyroid disease: a story of genes and environment. J Autoimmun 2009, 32(3-4):231-239.

3. McGrogan A, Seaman HE, Wright JW, de Vries CS: The incidence of autoimmune thyroid disease: a systematic review of the literature. Clin Endocrinol (Oxf) 2008, 69(5):687-696.

4. Fanciulli M, Petretto E, Aitman TJ: Gene copy number variation and common human disease. Clin Genet 77(3):201-213.

5. Schaschl H, Aitman TJ, Vyse TJ: Copy number variation in the human genome and its implication in autoimmunity. Clin Exp Immunol 2009, 156(1):12-16. 
6. Fanciulli M, Norsworthy PJ, Petretto E, Dong R, Harper L, Kamesh L, Heward JM, Gough SCL, de Smith A, Blakemore AIF, Owen CJ, Pearce SHS, Teixeira L, Guillevin L, Graham DSC, Pusey CD, Cook HT, Vyse TJ, Aitman TJ: FCGR3B copy number variation is associated with susceptibility to systemic, but not organ-specific, autoimmunity. Nature Genetics 2007 39(6):721-723.

7. Yang Y, Chung EK, Wu YL, Savelli SL, Nagaraja HN, Zhou B, Hebert M, Jones KN, Shu Y, Kitzmiller K, Blanchong CA, McBride KL, Higgins GC, Rennebohm RM, Rice RR, Hackshaw KV, Roubey RA, Grossman JM, Tsao BP, Birmingham DJ, Rovin BH, Hebert LA, Yu CY: Gene copy-number variation and associated polymorphisms of complement component $\mathrm{C} 4$ in human systemic lupus erythematosus (SLE): low copy number is a risk factor for and high copy number is a protective factor against SLE susceptibility in European Americans. Am J Hum Genet 2007, 80(6):1037-1054.

8. Yu CY, Whitacre CC: Sex, MHC and complement C4 in autoimmune diseases. Trends Immunol 2004, 25(12):694-699.

9. Carroll MC: The role of complement and complement receptors in induction and regulation of immunity. Annu Rev Immunol 1998, 16:545-568.

10. Liu YH, Chen RH, Chen WC, Tsai Y, Wan L, Tsai FJ: Disease association of the CD103 polymorphisms in Taiwan Chinese Graves' ophthalmopathy patients. Ophthalmology 117(8):1645-1651.

11. Szilagyi A, Blasko B, Szilassy D, Fust G, Sasvari-Szekely M, Ronai Z: Real-time $P C R$ quantification of human complement $C 4 A$ and $C 4 B$ genes. BMC Genet 2006, 7:1.

12. Zeitlin AA, Simmonds MJ, Gough SC: Genetic developments in autoimmune thyroid disease: an evolutionary process. Clin Endocrinol (Oxf) 2008, 68(5):671-682.

13. Jacobson EM, Tomer $Y$ : The genetic basis of thyroid autoimmunity. Thyroid 2007, 17(10):949-961

14. Fanciulli M, Norsworthy PJ, Petretto E, Dong R, Harper L, Kamesh L, Heward JM, Gough SC, de Smith A, Blakemore Al, Froguel P, Owen CJ, Pearce SH, Teixeira L, Guillevin L, Graham DS, Pusey CD, Cook HT, Vyse TJ, Aitman TJ: FCGR3B copy number variation is associated with susceptibility to systemic, but not organ-specific, autoimmunity. Nat Genet 2007, 39(6):721-723.

15. Markiewski MM, Lambris JD: The role of complement in inflammatory diseases from behind the scenes into the spotlight. Am J Pathol 2007, 171(3):715-727.

16. Davies EJ, Steers G, Ollier WE, Grennan DM, Cooper RG, Hay EM, Hillarby MC: Relative contributions of HLA-DQA and complement C4A loci in determining susceptibility to systemic lupus erythematosus. $\mathrm{Br} J$ Rheumatol 1995, 34(3):221-225.

17. Lachmann PJ: Complement deficiency and the pathogenesis of autoimmune immune complex disease. Chem Immunol 1990, 49:245-263.

18. Beurskens FJ, van Dijk H, Robins DM: Does complement component C4A protect from autoimmune disease? Immunol Today 1997, 18(4):199.

19. Seelen MA, Daha MR: The role of complement in autoimmune renal disease. Autoimmunity 2006, 39(5):411-415.

20. Chen M, Daha MR, Kallenberg CG: The complement system in systemic autoimmune disease. J Autoimmun 34(3):J276-286.

21. Trcka J, Moroi Y, Clynes RA, Goldberg SM, Bergtold A, Perales MA, Ma M, Ferrone CR, Carroll MC, Ravetch JV, Houghton AN: Redundant and alternative roles for activating $\mathrm{Fc}$ receptors and complement in an antibody-dependent model of autoimmune vitiligo. Immunity 2002, 16(6):861-868

22. Jin Y, Birlea SA, Fain PR, Gowan K, Riccardi SL, Holland PJ, Bennett DC, Herbstman DM, Wallace MR, McCormack WT, Kemp EH, Gawkrodger DJ, Weetman AP, Picardo M, Leone G, Taieb A, Jouary T, Ezzedine K, van Geel N, Lambert J, Overbeck A, Spritz RA: Genome-Wide Analysis Identifies a Quantitative Trait Locus in the MHC Class II Region Associated with Generalized Vitiligo Age of Onset. I Invest Dermatol 2011, Jun;131(6):1308-12, Epub 2011 Feb 17.

23. Quan $C$, Ren $Y Q$, Xiang $L H$, Sun LD, Xu AE, Gao XH, Chen HD, Pu XM, Wu RN, Liang CZ, Li JB, Gao TW, Zhang JZ, Wang XL, Wang J, Yang RY, Liang L, Yu JB, Zuo XB, Zhang SQ, Zhang SM, Chen G, Zheng XD, Li P, Zhu J, Li YW, Wei XD, Hong WS, Ye Y, Zhang Y, Wu WS, Cheng H, Dong PL, Hu DY, Li Y, Li M, Zhang X, Tang HY, Tang XF, Xu SX, He SM, LV YM, Shen M, Jiang HQ, Wang Y, Li K, Kang XJ, Liu YQ, Sun L, Liu ZF, Xie SQ, Zhu CY, Xu Q, Gao JP, Hu WL, Ni C, Pan TM, Yao S, He CF, Liu YS, Yu ZY, Yin XY, Zhang FY, Yang S, Zhou Y, Zhang XJ: Genome-wide association study for vitiligo identifies susceptibility loci at $6 q 27$ and the MHC. Nat Genet 42(7):614-618

doi:10.1186/1423-0127-18-71

Cite this article as: Liu et al.: Association between copy number variation of complement component C4 and Graves' disease. Journal of Biomedical Science 2011 18:71.

\section{Submit your next manuscript to BioMed Central and take full advantage of:}

- Convenient online submission

- Thorough peer review

- No space constraints or color figure charges

- Immediate publication on acceptance

- Inclusion in PubMed, CAS, Scopus and Google Scholar

- Research which is freely available for redistribution

Submit your manuscript at www.biomedcentral.com/submit
Ciomed Central 